\title{
Microwave signatures of ice hydrometeors from ground-based observations above Summit, Greenland
}

\author{
Claire Pettersen $^{1}$, Ralf Bennartz ${ }^{1,2}$, Mark S. Kulie ${ }^{1}$, Aronne J. Merrelli ${ }^{1}$, Matthew D. Shupe ${ }^{3}$, and David D. Turner ${ }^{4}$ \\ ${ }^{1}$ Space Science and Engineering Center, Madison, Wisconsin, USA \\ ${ }^{2}$ Vanderbilt University, Nashville, Tennessee, USA \\ ${ }^{3}$ Cooperative Institute for Research in Environmental Science, University of Colorado and NOAA - Earth System Research \\ Laboratory, Boulder, Colorado, USA \\ ${ }^{4}$ National Severe Storms Laboratory, Norman, Oklahoma, USA
}

Correspondence to: Claire Pettersen (claire.pettersen@ssec.wisc.edu)

Received: 21 August 2015 - Published in Atmos. Chem. Phys. Discuss.: 8 December 2015

Revised: 13 March 2016 - Accepted: 31 March 2016 - Published: 15 April 2016

\begin{abstract}
Multi-instrument, ground-based measurements provide unique and comprehensive data sets of the atmosphere for a specific location over long periods of time and resulting data compliment past and existing global satellite observations. This paper explores the effect of ice hydrometeors on ground-based, high-frequency passive microwave measurements and attempts to isolate an ice signature for summer seasons at Summit, Greenland, from 2010 to 2013. Data from a combination of passive microwave, cloud radar, radiosonde, and ceilometer were examined to isolate the ice signature at microwave wavelengths. By limiting the study to a cloud liquid water path of $40 \mathrm{~g} \mathrm{~m}^{-2}$ or less, the cloud radar can identify cases where the precipitation was dominated by ice. These cases were examined using liquid water and gas microwave absorption models, and brightness temperatures were calculated for the high-frequency microwave channels: 90, 150, and $225 \mathrm{GHz}$. By comparing the measured brightness temperatures from the microwave radiometers and the calculated brightness temperature using only gas and liquid contributions, any residual brightness temperature difference is due to emission and scattering of microwave radiation from the ice hydrometeors in the column. The ice signature in the 90,150 , and $225 \mathrm{GHz}$ channels for the Summit Station summer months was isolated. This measured ice signature was then compared to an equivalent brightness temperature difference calculated with a radiative transfer model including microwave single-scattering properties for several ice habits. Initial model results compare well against the 4
\end{abstract}

years of summer season isolated ice signature in the highfrequency microwave channels.

\section{Introduction}

Better characterization of precipitation in the Arctic is fundamental to improve our understanding of the hydrological cycle and mass balance of the polar ice sheets. The Greenland Ice Sheet (GIS) is of particular interest as it has relatively large impacts on the Earth's climate system (Church, 2001). Understanding the characteristics of precipitation above the GIS is a key factor in quantifying the full energy and ice mass balance. Accurate atmospheric measurements and remote sensing precipitation retrievals from multiple instruments are essential to resolving and refining precipitation estimates over the GIS.

Microwave radiometers (MWRs) are a common remote sensing instrument, which make passive measurements of radiance at specific frequencies. Typically, MWR measurements are used to retrieve atmospheric properties, specifically liquid water path and precipitable water vapor (LWP and PWV, respectively). A frequently implemented technique for characterizing ice hydrometers from satellites and aircraft is to use high-frequency microwave channels (89 GHz and greater) and look for depressed brightness temperatures due to scattering of the upwelling radiation to calculate an ice water path (Hong et al., 2005; Bennartz and Bauer, 2003; Kulie and Bennartz, 2009; Deeter and Evans, 
2000). While liquid and gas in the atmospheric column absorb and emit microwave radiation, ice hydrometeors scatter surface radiation away from the satellite sensor and depress the observed brightness temperature (BT). The same technique can be used from the ground looking up with the opposite effect, as ice scatters the upwelling radiation back towards the MWR sensor. Kneifel et al. (2010; hereafter K10) demonstrated the presence of an enhanced BT signature from ice hydrometeors in downwelling microwave radiance observations for a case study of snowfall in the Alps using ground-based MWRs. The high-frequency channels (90 and $150 \mathrm{GHz}$ ) are considered "window channels", since these frequencies are free of strong gas absorption lines. At these frequencies the clear-sky downwelling radiance is very small, so when ice or liquid water is present these channels see a warmer BT, as seen by the K10 study.

If there are ice hydrometeors present in the atmosphere column, they will have two effects on the observed downwelling radiance at the surface: emission of radiation and scattering of the surface-emitted radiation back to the instrument. In general, ice hydrometeors have fairly high single scatter albedo (SSA) at high microwave frequencies, regardless of habit and size distribution. Typically the SSA will be in the range 0.8-0.9 (Liu, 2008), which implies that scattered radiation is likely the larger effect, but there may still be significant emitted radiation from the ice hydrometeors. Since some of the ice signature is scattered surface radiation, the magnitude of the effect is related to both the surface temperature and emissivity. The surface emissivity of different types of snow seen at Summit varies in the range of 0.60 to 0.91 for the higher-frequency passive microwave channels used in this study (Yan et al., 2008). This makes the ice signature challenging to model because it depends on both properties of the ice hydrometeors (habit, size distribution, amount, etc.) and the surface (temperature, roughness, emissivity).

We propose that the enhanced BT from the ice hydrometeors can be isolated and quantified by combining the observed data from instruments in the Integrated Characterization of Energy, Clouds, Atmospheric State, and Precipitation at Summit project (ICECAPS; Shupe et al., 2013) with radiative transfer models of the gas and liquid in the atmosphere. By doing this we are enhancing the K10 study by expanding it to multiple years of data in an Arctic environment with very low amounts of liquid water and precipitable water vapor, which present unique challenges. Additionally, since the temperatures at Summit Station are below freezing, we are implementing a newly developed cloud liquid water model for more accurate retrievals in the presence of supercooled water (Kneifel et al., 2014; Turner et al., 2015). Because the ice signature is also dependent on ice crystal habit and size distribution, relying on a small number of precipitation events to derive the ice signature may bias the result toward specific precipitation situations. The large data set from the ICECAPS Project allows for the average ice signature to be computed over many precipitation events, thus reducing this potential sampling bias.

In this paper we use the ICECAPS instrument suite (described in Sect. 2) to resolve a signal from the ice hydrometeors present in the high frequency, ground-based MWRs (90, $150,225 \mathrm{GHz}$ ) for multiple years of summer season data at Summit, Greenland. We modeled the gas and liquid present in the column and compared that to observations from the MWRs (Sect. 3). We had to develop a technique to accurately model the absorption/emission from the liquid water and atmospheric gases; this is described in Sect. 4. Finally, we demonstrate an initial scattering model of the ice and compare these results to the observed signature (Sect. 5).

\section{Data sets and methods}

Studying the seasonal characteristics of the ice hydrometeors above the GIS is made possible with observations from the ICECAPS instrument suite from 2010 to 2013. Model results are then combined or compared with observations from specific instruments in the ICECAPS suite.

\subsection{ICECAPS project and instrument suite}

Summit Station was the site of the Greenland Ice Sheet Project 2 (GISP2) ice core project, and has been expanded to a continuously operational science facility dedicated to studying the atmosphere and ice sheet properties of the GIS (Dansgaard et al., 1993). Summit Station is home to many atmospheric and snow science instruments, including ICECAPS, which is purposely co-located at Summit Station to aid in understanding the cloud and atmosphere properties over the GIS and their interaction with the cryosphere. Since 2010, the ICECAPS suite of instruments has been monitoring a variety of atmospheric parameters to further our knowledge of atmospheric processes above the GIS (Shupe et al., 2013). The ICECAPS project will remain at Summit until at least 2018, thus providing a comprehensive data set and analyses of the atmosphere over central Greenland. Additionally, ICECAPS is expanding the network of past and existing highlatitude atmospheric suites (i.e., Eureka, Canada and Barrow, Alaska, Ny-Ålesund) already helping to characterize Arctic atmospheric and cloud processes (Shupe et al., 2011; Uttal et al., 2015).

ICECAPS is modeled after other successful Arctic observatories and is similar in scope to facilities run by the Department of Energy's Atmospheric Radiation Measurement (ARM) program (Ackerman and Stokes, 2003; Shupe et al., 2013). The ICECAPS instrument suite is supported by yearround technicians and support staff at Summit Station and is updated with new instruments, upgrades, and repairs by researchers every summer. Table 1 illustrates a brief overview of the ICECAPS instruments used in this study, including key specifications, measurements, and retrieved parameters. We 
Table 1. Sub-group of ICECAPS suite instruments used in this study (modified from Table 1 in Shupe et al., 2013).

\begin{tabular}{|c|c|c|c|}
\hline Instrument name & Specifications & Measurements & Derived parameters \\
\hline HATPRO & $\begin{array}{l}\text { Frequencies: } \\
22-32 \mathrm{GHz} \text { ( } 7 \text { channels); } \\
51-58 \mathrm{GHz} \text { ( } 7 \text { channels); } \\
2 \text { to } 4 \text { s resolution }\end{array}$ & $\begin{array}{l}\text { Downwelling brightness } \\
\text { temperature }\end{array}$ & Cloud LWP and PWV \\
\hline MWRHF & $\begin{array}{l}\text { Frequencies: } \\
90 \text { and } 150 \mathrm{GHz} \\
2 \text { to } 4 \text { s resolution }\end{array}$ & $\begin{array}{l}\text { Downwelling brightness } \\
\text { temperature }\end{array}$ & Cloud LWP and PWV \\
\hline MMCR & $\begin{array}{l}35 \mathrm{GHz} \text { (Ka band); } \\
8 \mathrm{~mm} \text { wavelength; } \\
45 \mathrm{~m} \text { vertical bin size; } \\
2 \mathrm{~s} \text { resolution }\end{array}$ & $\begin{array}{l}\text { Reflectivity, Doppler veloc- } \\
\text { ity, Doppler spectral width }\end{array}$ & $\begin{array}{l}\text { Cloud micro- and macro-physics } \\
\text { Cloud dynamics }\end{array}$ \\
\hline Ceilometer & $\begin{array}{l}905 \mathrm{~nm} \text { wavelength; } \\
15 \mathrm{~m} \text { vertical resolution; } \\
15 \mathrm{~s} \text { resolution }\end{array}$ & Backscatter & Cloud-base height \\
\hline $\begin{array}{l}\text { RS-92K or } \\
\text { RS-92SGP Radiosondes }\end{array}$ & $\begin{array}{l}\text { Twice daily }(00: 00 \text { and } \\
12: 00 \mathrm{Z}) \\
1 \mathrm{~s} \text { resolution }\end{array}$ & $\begin{array}{l}\text { Temperature, relative } \\
\text { humidity, pressure, winds }\end{array}$ & $\begin{array}{l}\text { Cloud temperature, tropospheric } \\
\text { thermodynamic structure }\end{array}$ \\
\hline MWRHF-225 & $\begin{array}{l}\text { Frequency: } \\
225 \mathrm{GHz} \\
4 \text { s resolution }\end{array}$ & $\begin{array}{l}\text { Downwelling brightness } \\
\text { temperature }\end{array}$ & Atmospheric opacity \\
\hline
\end{tabular}

employed data from a subgroup of the ICECAPS suite and a co-located $225 \mathrm{GHz}$ MWR. The available measurements and retrieved values are further described in the following sections.

\subsubsection{Millimeter cloud radar}

The Millimeter Wavelength Cloud Radar (MMCR) is a zenith pointing, $35 \mathrm{GHz}$ (Ka band) radar with processed measurements provided every $10 \mathrm{~s}$ at a height resolution of $45 \mathrm{~m}$ (Moran et al., 1998). The MMCR measures the profile of reflectivity, Doppler velocity, and Doppler spectral width in the column above. For the MMCR, hydrometeors with geometric diameters less than approximately $3 \mathrm{~mm}$ are in the Rayleigh scattering region (Kneifel et al., 2011). However, for ice hydrometeors larger than $\sim 3 \mathrm{~mm}$ diameter the Rayleigh approximation breaks down (at this size, the MMCR starts to see Mie resonance effects) and the backscatter cross section depends on ice habit (Kneifel et al., 2011; Petty and Huang, 2010).

The Doppler velocity measures the fall speed of particles toward the radar - this is dependent on the mass and projected area of the ice hydrometer population; thus, some micro-physical insight is gained from these fall speed values. However, the particles are embedded with a vertical wind field that will affect the measured fall speed.

Finally, the variance of the velocity in a given pulse volume, the Doppler spectral width, aids in determining turbulence and contains indicators of hydrometeor phase. Strong turbulence or multiple phases/habits in a cloud layer leads to large a Doppler spectral width. On the other hand, uni- form particle populations, such as for those precipitating out of a cloud, exhibit relatively low Doppler spectral width. By combining these measured quantities from the MMCR, we can infer many properties of the hydrometeors observed at Summit.

\subsubsection{Microwave radiometers}

ICECAPS also gathers observations from three different passive MWRs all built by Radiometer Physics GmbH. The $\mathrm{Hu}-$ midity and Temperature Profiler (HATPRO) has seven channels from 22 to $32 \mathrm{GHz}$ (near $22.24 \mathrm{GHz}$ water vapor absorption line) and seven channels from 51 to $58 \mathrm{GHz}$ (near oxygen absorption line; Rose et al., 2005). The high-frequency microwave MWR (MWRHF) has two high-frequency channels: 90 and $150 \mathrm{GHz}$. The two radiometers are run in a master-slave configuration and make coincident measurements every $4 \mathrm{~s}$. Data from the third co-located MWR, which is sponsored by the Academia Sinica Institute of Astronomy and Astrophysics (ASIAA) group, observes downwelling radiation at $225 \mathrm{GHz}$, and takes measurements every $4 \mathrm{~s}$ (Matsushita et al., 2013). Although all of the MWRs measure the downwelling atmospheric radiance at several elevation angles, in this study we only use data from zenith pointing.

Passive microwave radiometry is commonly used to derive liquid water path (LWP; Crewell et al., 2009). By combining the BTs observed from specific channels, PWV and LWP are derived. Historically, LWP and PWV at ARM sites are derived using the 23.84 and $31.40 \mathrm{GHz}$ channels using a version of the MWR retrieval (MWRRET) algorithm (Turner et al., 2007a). The physical retrieval method employs the 
MonoRTM radiative transfer model (Clough et al., 2005) and the Liebe91 liquid water model (Liebe, 1991). It was found that the addition of high-frequency channels to the retrieval algorithm improves LWP accuracy, particularly for low LWP amounts. By adding the $90 \mathrm{GHz}$ channel, the uncertainty is reduced from 20 to $30 \mathrm{~g} \mathrm{~m}^{-2}$ to better than $12 \mathrm{~g} \mathrm{~m}^{-2}$ (Crewell and Löhnert, 2003; Löhnert and Crewell, 2003). The four channel MWRRETv2, which includes the addition of the 90 and $150 \mathrm{GHz}$ channels, calculates an uncertainty of 4 $5 \mathrm{~g} \mathrm{~m}^{-2}$ for typical retrievals at Summit (MWRRETv2).

The reduced uncertainty at low LWPs is important to this study, as the cloud liquid water path on average at Summit (and the Arctic as a whole) is small as $80 \%$ of liquid-bearing clouds in the Arctic have less than $100 \mathrm{~g} \mathrm{~m}^{-2}$ LWP (Turner et al., 2007b). However, the K10 study showed that highfrequency channels have enhanced brightness temperatures when ice is present in the column. Additionally, recent studies have indicated that many liquid water absorption models do a poor job adequately accounting for supercooled cloud liquid water (Turner et al., 2015; hereafter TKC15). We compared results from four channel MWRRETv2 retrievals using both the Liebe91 and TKC15 models. We found that the MWRRET retrieval had improved convergence when using TKC15 versus the Liebe91 cloud liquid water model, especially in the difficult to resolve ice affected cases. To further mitigate the effect of the enhanced BTs in the highfrequency channel, we opted to use MWRRETv2 with the TKC15 model and only three channels to compute LWP and PWV: $23.84,31.40$, and $90 \mathrm{GHz}$. Due to computational expense, the MWRRET retrieval is run on the MWR data every $100 \mathrm{~s}$.

\subsubsection{Ceilometer}

The MWRRET retrieval gives the integrated cloud liquid water amount but no information about cloud altitude. Cloudbase height $(\mathrm{CBH})$ is estimated from a Vaisala Ceilometer (VCEIL). The VCEIL is a vertically pointing $905 \mathrm{~nm}$ pulsed laser system with $15 \mathrm{~m}$ height resolution and takes a measurement every $15 \mathrm{~s}$. Cloud-base heights (up to three layers) are determined based on the backscattered signal received by the instrument. We use the first cloud-base height retrieved from the VCEIL to define the base of the cloud liquid water layer in this study.

\subsubsection{Radiosondes}

This study also uses data from twice daily balloon-borne radiosondes (manufactured by Vaisala, models RS-92K and RS-92SGP) launched at Summit Station. The launches occur at approximately 1200 and 2400 Coordinated Universal Time (UTC), and gather in situ measurements of temperature, pressure, relative humidity, and, in some cases, horizontal wind speed and direction. These thermodynamic profiles provide critical input for the radiative transfer modeling (see Sect. 2.2).

\subsubsection{Merged data}

The data sets described above are merged together to a common sampling time, defined by the MWRRET retrieval (every $100 \mathrm{~s}$ ). The slower data stream (twice daily radiosonde) is linearly interpolated to the common sampling time, and the faster data streams are simply subsampled at the MWRRET retrieval times. We interpolate all the data to the fixed height grid defined by the MMCR.

For an example day, we use data from the prior day's radiosonde launch (day - 1, 24:00 UTC) along with the two radiosondes launched for the given day (12:00 and 24:00 UTC) and linearly interpolate the temperature, pressure, and relative humidity of each layer in the column throughout the day to the MWRRET temporal grid. The vertical layering uses the MMCR vertical grid up to $7.5 \mathrm{~km}$ altitude above ground level (a.g.l.). Above this altitude, the layering becomes gradually coarser and extends to up $30 \mathrm{~km}$ a.g.l. Next, the MWR retrieved PWV is used to scale the interpolated relative humidity from the radiosonde - this is because the PWV retrieved value is higher temporal resolution and more accurate than the radiosonde data (Turner et al., 2003). Finally, a single layer cloud is inserted into the vertical grid at the first cloud-base height (CBH1) detected by the VCEIL, with the MWR retrieved LWP value.

\subsection{Absorption coefficients for gas and liquid water}

The emission and absorption of the gases and liquid water in the atmospheric column are modeled using in situ observations of temperature and pressure and remotely sensed values of integrated water vapor, liquid water content, and cloudbase height from the ICECAPS instruments. To compute the volume absorption coefficients of dry air and water vapor in the atmospheric column, we employed the MonoRTM (v5.0; Clough et al., 2005) using inputs of layer temperature, pressure, and scaled water vapor. The liquid water absorption and emission is modeled using the TKC15 model (Turner et al., 2015 ) with inputs of liquid water content (LWC) at a defined cloud height and temperature. For altitudes above the radiosonde profile, a subarctic standard atmosphere profile is assumed. The simulated emission is not sensitive to the details of the upper atmosphere profile, but systematic biases would be present if the atmosphere was artificially truncated at too low an altitude.

\subsection{Successive-order-of-interaction radiative transfer model}

In ice-cloud-free atmospheres, the RT model need only consider the absorption and emission of atmospheric gases and liquid water. When ice is introduced into the column, multiple scattering can occur and we then must employ a radiative 
transfer model that accounts for scattering. The successiveorder-of-interaction (SOI) RT model accurately simulates scattering for the infrared and microwave spectral region (Heidinger et al., 2006; O'Dell et al., 2006). The SOI model combines the layer-averaged optical properties and temperature in order to compute downwelling radiance at selected frequencies. The layer-averaged optical properties are calculated from the gas and liquid water absorption models (described above) and ice optical properties (further discussed in Sect. 5). The SOI modeled BTs can then be compared to MWR observations. For all cases used in this study we employed the SOI radiative transfer model, even when modeling non-scattering atmospheres that only include gases and cloud liquid water absorption. As is further discussed in the subsequent section, comparing the measured and modeled BTs at specific frequencies lends insight into the hydrometers present in the atmospheric column.

\section{Ice hydrometeor behavior as observed by ICECAPS}

Similar to K10, we compared the BTs in the high-frequency channels of the MWRs to the output from the radiative transfer model calculation. The K10 study employed a radiative transfer model that included absorption/emission and scattering to simulate the behavior of the ice signature based on the habit, surface emissivity, etc. Different from K10, we do not initially include an ice scattering model for the purpose of identifying the ice signature. We instead attempt to isolate the ice radiative signature in the observations by accounting for any other potential emission or absorption sources within the column. If we compare the calculated BT using only gas and liquid water to the observed BTs from the MWRHF, any difference should be due to the ice signature. Consequently, the average ice hydrometeor radiative signature can be computed over many precipitation events by extending the analysis to the full available ICECAPS data set.

\subsection{Characterization of ice precipitation at Summit}

We can acquire statistics of different precipitation regimes at Summit by merging all available MMCR data and plotting contoured frequency by altitude diagrams (CFADs). CFADs depict all data as a two-dimensional occurrence histogram, with the vertical axis representing the height dimension and the horizontal axis representing a radar measurement (for example, reflectivity). Figure $1 \mathrm{a}$ is a CFAD of all the reflectivity values measured by the MMCR for any given time within the summer months - June, July, August (JJA) - 2010 through 2013. We can highlight the types of hydrometeors observed during specific atmospheric conditions by filtering the MMCR reflectivity CFAD, illustrated in Fig. 1a, as a function of other ICECAPS instrument measurements or derived parameters.
Filtering the MMCR CFADs by the corresponding MWRderived LWP for the same time period can identify regimes in which ice hydrometeors are likely present. We partition the data with a threshold LWP value in order to select cases that have low LWP. The exact threshold value is arbitrary, as the resulting CFADs are not sensitive to the particular threshold value. We tried values of 5,10 , and $40 \mathrm{~g} \mathrm{~m}^{-2}$ and observed qualitatively similar CFADs. We selected a $40 \mathrm{~g} \mathrm{~m}^{-2}$ LWP threshold for the remaining analysis, since this yielded a larger number of cases for the study (as opposed to the lower LWP threshold values).

As depicted in Fig. $1 b$ and $c$, the MMCR reflectivity CFAD for JJA has been filtered by cases when LWP was less than and greater than $40 \mathrm{~g} \mathrm{~m}^{-2}$, respectively. The resulting CFADs have different characteristics from each other and lend insight to the behaviors of the hydrometeors in each case. For the case of LWP less than $40 \mathrm{~g} \mathrm{~m}^{-2}$, the CFAD illustrates common ice hydrometeor behaviors: a fall-streak-like pattern of increasing reflectivity with decreasing height and peak near-surface reflectivities above $0 \mathrm{dBZ}$ (see Fig. 1b). In contrast, the reflectivity CFAD for the cases where LWP is greater than $40 \mathrm{~g} \mathrm{~m}^{-2}$ has a concentration of counts at a broader range of smaller reflectivities located at lower altitude, likely indicating dominance of shallow mixed ice and supercooled water cloud (though there is also a faint signal indication of some fall-streak behavior; see Fig. 1c). The reflectivities shown in Fig. $1 \mathrm{~b}$ for less than $40 \mathrm{~g} \mathrm{~m}^{-2}$ LWP cases have characteristics of deep, precipitating ice cloud, while the greater than $40 \mathrm{~g} \mathrm{~m}^{-2}$ LWP cases show features similar to the shallow mixed-phase stratocumulus (Fig. 1c). Additionally, Fig. 1 panels d through i depict the Doppler velocities and spectral width measurements from the MMCR as CFADs for all LWPs, less than $40 \mathrm{~g} \mathrm{~m}^{-2}$, and greater than $40 \mathrm{~g} \mathrm{~m}^{-2}$. The features seen in the Doppler velocity and spectral width CFADs for the cases less than $40 \mathrm{~g} \mathrm{~m}^{-2}$ are consistent with the characteristics of deep, precipitating ice cloud (high fall speeds and low spectral widths throughout the column, relative to greater than $40 \mathrm{~g} \mathrm{~m}^{-2}$ LWP cases).

The frequency of cases in JJA where the LWP is greater than $40 \mathrm{~g} \mathrm{~m}^{-2}$ is $\sim 22 \%$, while the cases where LWP is less than $40 \mathrm{~g} \mathrm{~m}^{-2}$ is $\sim 63 \%$ of the time, and clear sky is the remaining $15 \%$ of cases (i.e., where the MMCR reflectivity is less than $-60 \mathrm{dBZ}$ ). To maximize the likelihood of observing ice dominated cases, we limit our work to focus on cases in JJA with LWP of less than $40 \mathrm{~g} \mathrm{~m}^{-2}$. As stated above, the cases with LWP greater than $40 \mathrm{~g} \mathrm{~m}^{-2}$ show features consistent with the shallow mixed-phase stratocumulus and by filtering out some of these events, we can better focus the study on the deeper, precipitating ice clouds. Since cases with LWP of less than $40 \mathrm{~g} \mathrm{~m}^{-2}$ represent the majority at Summit during the summer months, we can use this filter to get an accurate characterization of ice hydrometeor behavior while limiting interference from higher liquid water path.

We argue that the large radar reflectivity values are directly correlated to ice backscatter and cannot be from liquid pre- 

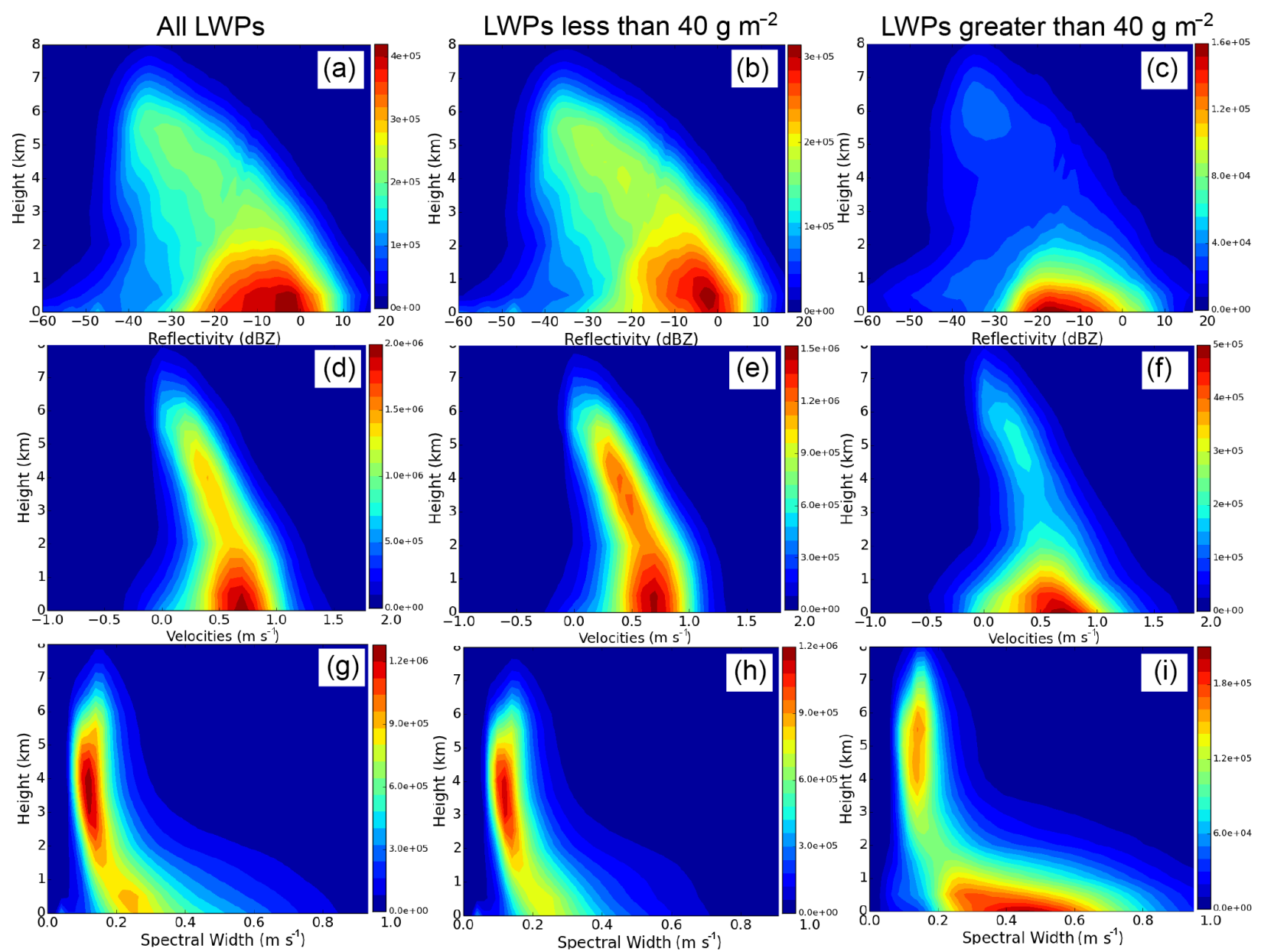

Figure 1. CFADs of MMCR reflectivity for summer (JJA) at Summit, Greenland, from June 2010 to August 2013 with a sample resolution rate every $10 \mathrm{~s}$. Panel (a) shows JJA reflectivity for all measured LWPs while panel (b) is filtered to reflectivities only when LWP is less than $40 \mathrm{~g} \mathrm{~m}^{-2}$ and panel (c) is filtered for cases greater than $40 \mathrm{~g} \mathrm{~m}^{-2}$. Additional CFADs of MMCR Doppler velocity and spectral width for summer at Summit, Greenland, for all LWPs (d, g), when LWP is less than $40 \mathrm{~g} \mathrm{~m}^{-2}$ (e, h), and when LWP is greater than $40 \mathrm{~g} \mathrm{~m}^{-2}(\mathbf{f}, \mathbf{i})$, respectively. LWP less than $40 \mathrm{~g} \mathrm{~m}^{-2}$ accounted for $\sim 63 \%$ of cases, while greater than $40 \mathrm{~g} \mathrm{~m}^{-2}$ is $22 \%$ of cases, and the remaining $15 \%$ is clear sky (as determined by the MMCR).

cipitation, as Summit is never above freezing and thus large liquid hydrometeors (greater than $80 \mu \mathrm{m}$ diameter) are highly unlikely to occur (Pruppacher and Klett, 2000). Since we do not expect to see liquid hydrometeors larger than cloud droplets at Summit Station, MMCR observed reflectivities greater than $-15 \mathrm{dBZ}$ should be indicative of ice (Frisch et al., 1995).

\subsection{Enhanced brightness temperatures in the high-frequency channels}

As postulated from previous case studies in K10, the higherfrequency channels in the ground-based zenith-pointing MWRs will see an enhanced BT in the presence of ice in the column. Thus, we examine the difference between the measured BTs from the 90 and $150 \mathrm{GHz}$ channels and the SOI model outputs (with no ice included, gas and liquid wa- ter contributions only) at that same frequency. As illustrated in the contour plot of the JJA comparison in Fig. $2 \mathrm{c}$ and d, there is an increase in the difference of the observed minus modeled BTs as a function of the MMCR reflectivity converted to what we refer to as " $Z_{\mathrm{PATH}}$ ", though very small in the $90 \mathrm{GHz}$ channel.

The $Z_{\text {PATH }}$ is simply the column integrated reflectivities with units of $\mathrm{mm}^{6} \mathrm{~m}^{-2}$. This MMCR $Z_{\text {PATH }}$ measurement is related to the total amount of hydrometeor backscatter in the atmospheric column. The use of $Z_{\mathrm{PATH}}$ is advantageous because it acts as a proxy for ice water path (IWP) yet does not rely on conversions that are sensitive to ice habit (Kulie et al., 2010). $Z_{\text {PATH }}$ is defined as

$Z_{\mathrm{PATH}}=\int 10^{0.1 \cdot R(z)} \mathrm{d} z$. 


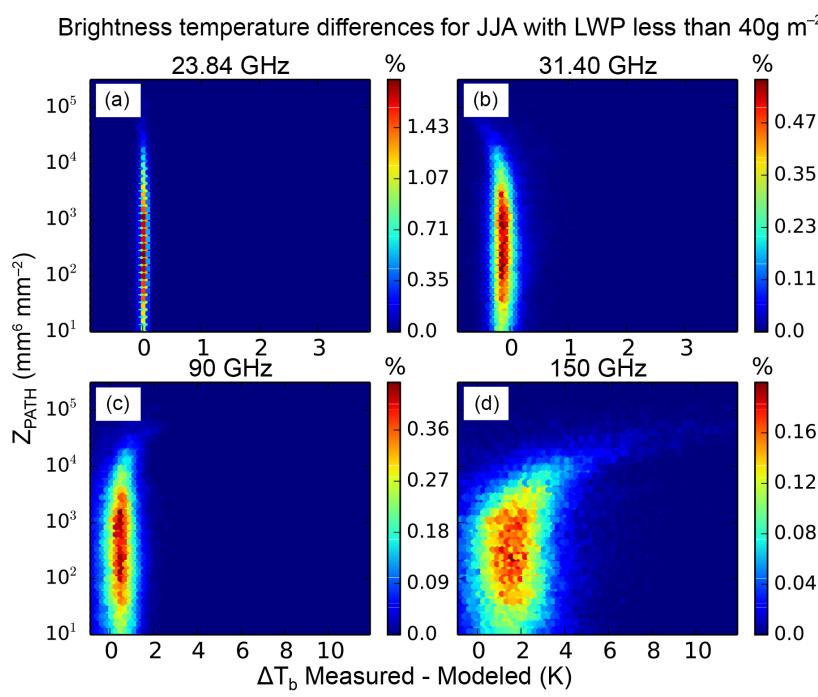

Figure 2. Brightness temperature differences between observations minus the modeled gas and liquid contributions in the 23.84, 31.40, 90 , and $150 \mathrm{GHz}$ channels as a function of $Z_{\mathrm{PATH}}$ for LWP less than $40 \mathrm{~g} \mathrm{~m}^{2}$. The count histogram is binned logarithmically in $Z_{\text {PATH }}$ and linearly in $\Delta T_{\mathrm{b}}$, shown as percentage of total observation count per bin. The $150 \mathrm{GHz}$ channel shows an enhanced BT difference with respect to $Z_{\text {PATH }}($ d), while the $90 \mathrm{GHz}$ has a slight enhanced BT, the $31 \mathrm{GHz}$ exhibits a negative dependence, and the $23.84 \mathrm{GHz}$ is channel neutral.

Where $R(z)$ is the observed radar reflectivity profile in units of dBZ.

The observed minus modeled BT differences at 90 and $150 \mathrm{GHz}$ have a clear positive dependence on $Z_{\mathrm{PATH}}$. As stated in the previous section, we do not expect to see any liquid hydrometeors at reflectivities greater than $-15 \mathrm{dBZ}$ at Summit since there is no "warm rain" process, which means that large $Z_{\text {PATH }}$ values are indicative of ice. Therefore, the relationship between the BT differences at 90 and $150 \mathrm{GHz}$ and the MMCR $Z_{\text {PATH }}$ suggest that the enhanced BT signature is caused by ice hydrometeors.

\subsection{Depressed brightness temperatures at $31.40 \mathrm{GHz}$}

The lower-frequency channels ( 23.84 and $31.40 \mathrm{GHz}$ ) should exhibit little to no effect from the presence of ice hydrometeors in the atmospheric column, as the microwave radiation at these frequencies is comparatively insensitive to ice hydrometeors (Johnson et al., 2012). Thus, we expect the histogram contours to be nearly vertical at the 23.84 and $31.40 \mathrm{GHz}$ for the relationship between the BT differences and the integrated reflectivity $\left(Z_{\mathrm{PATH}}\right)$. However, as seen in Fig. $2 \mathrm{~b}$, the $31.40 \mathrm{GHz}$ channel shows a clear negative dependence on $Z_{\text {PATH }}$ at the highest values. There is no physical mechanism by which ice hydrometeors could decrease the observed downwelling radiance. This result implies an issue with the input values implemented in the radiative transfer model, as it is unlikely for the low-frequency channels at 23.84 and $31.40 \mathrm{GHz}$ to see much contribution from ice in the column.

Two of the inputs for the radiative transfer model are retrieved values based on BTs from the MWRs: the PWV and LWP. As explained in Sect. 2.1.2., the retrieval for the PWV and LWP employ a three-channel algorithm, which includes the $90 \mathrm{GHz}$ channel. Though we tried to mitigate the effect of the ice by using the three-channel algorithm, the enhanced BT in the $90 \mathrm{GHz}$ still has a significant impact on the retrieved LWP and PWV. More precisely, the retrieval will tend to adjust the LWP and PWV in order to account for the enhanced BT from the ice hydrometeors, leading to an overestimate of LWP and underestimate of PWV.

\section{Liquid water path retrieval influenced by ice}

As postulated in the previous section, we believe that the MWR retrieved LWP (PWV) values are biased high (low) when a significant ice signature is present in the column due to the retrieval incorporating the $90 \mathrm{GHz}$ MWR channel. However, if we use only a retrieval based on the lower frequencies of 23.84 and $31.40 \mathrm{GHz}$, the random error in LWP increases dramatically to $20-30 \mathrm{~g} \mathrm{~m}^{-2}$, which is a large fractional error $(>50 \%)$. Thus, a relationship for the LWP and PWV biases in the three-channel retrieval as a function of the MMCR derived $Z_{\text {PATH }}$ must be determined to accurately distinguish the ice signature. We developed a first-order correction of the estimated MWRRET retrieval biases, where the intention of this correction is to recover the ice signature, not to produce a formal correction to the ice-influenced LWP and PWV retrievals.

\subsection{Ice signature influence on retrieved liquid water}

As illustrated in Fig. 2, the difference between measured and modeled BTs as a function of $Z_{\mathrm{PATH}}$, analogous to the amount of ice in the column, decreases in the $31.40 \mathrm{GHz}$ channel. This effect is an artifact in the simulated BTs caused by the following chain of events:

1. The presence of ice increases the observed BTs at $90 \mathrm{GHz}$ but has little effect on the lower frequencies.

2. Since the retrieval does not include effects from ice, the retrieval accounts for this enhanced signal in the $90 \mathrm{GHz}$ channel by increasing (decreasing) the retrieved LWP (PWV) thus producing a positively (negatively) biased LWP (PWV) estimate.

3. Since the spectral absorption for the three water states (vapor, liquid, ice) have different shapes, the retrieval cannot reduce the modeled-measured BT bias to zero for all channels.

To better illustrate this idea it is useful to look at Fig. 2 from $\mathrm{K} 10$, where the optical thickness as a function of frequency 

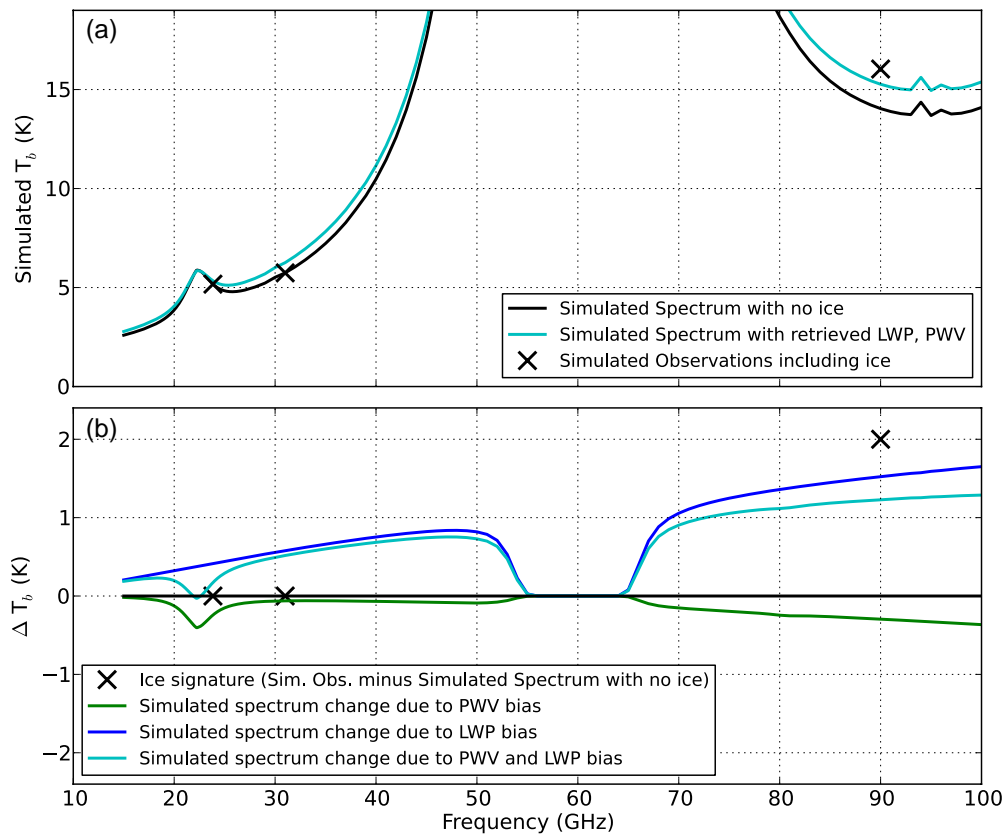

Figure 3. Panel (a) shows the simulated downwelling microwave radiance spectrum with no ice (black) and the simulated spectrum with the biased PWV and LWP obtained by the retrieval (cyan). Panel (b) shows the simulated data after subtracting the simulated spectrum with no ice. The effect of the biased LWP and PWV on the microwave spectrum are shown independently (blue and green lines, respectively) and combined (cyan line). The " $\mathrm{X}$ " marks show the simulated ice influence at 23.84, 31.40, and $90 \mathrm{GHz}$.

is plotted for several absorption models - water vapor, liquid water, ice by habit, etc. The liquid water and ice total optical depths $(\tau)$ are less than 0.2 for these frequencies. Since the total $\tau$ is low, we can make two simplifying approximations: first, the transmission to any atmospheric layer in the column is nearly 1 ; and second, the change in transmission through a layer is approximately the change in $\tau$ for that layer. This implies the BTs are a linear combination of $\tau$ for each atmospheric component.

The bias in the simulated BT, shown in Fig. 2, suggests that the MWRRET retrieved PWV and LWP may be influenced by the presence of ice hydrometeor signature in the $90 \mathrm{GHz}$ channel used in the retrieval. Since the MWRRET does not include ice hydrometeors in the radiative transfer calculation, it can only fit retrieval channel observations by adjusting the PWV and LWP. The higher optical depth for liquid water at $90 \mathrm{GHz}$ suggests that MWRRET adds extra LWP to account for the observed microwave ice signature. This will increase the forward modeled BT for the 23.84 and $31.40 \mathrm{GHz}$ channels as well. Since there will be effectively zero ice signature at the low-frequency MWR observations, the extra LWP will cause the low-frequency BTs to be biased high. The retrieval partially compensates for the high BT bias at low frequencies by decreasing the PWV, which will reduce the simulated BT primarily at the $23.84 \mathrm{GHz}$ channel, which is near the water vapor absorption line. Figure 3 shows these biases in a schematic fashion. Because the liquid absorption model uses the MWR retrieved LWP and PWV as inputs to the SOI, a correction for the retrieved LWP and PWV in the presence of ice is necessary to accurately quantify the ice impact on passive microwave BTs.

\subsection{Ice-influenced liquid water path correction}

The lower-frequency channels are comparably insensitive to ice (Johnson et al., 2012), so we focus on the 23.84 and $31.40 \mathrm{GHz}$ channels to derive a first-order estimate for the MWRRET LWP and PWV biases from the ice signature. In order to correct for the apparently biased PWV and LWP, we make an ad hoc linear correction to the retrieved values. We assume the PWV and LWP bias are linearly related to the $Z_{\mathrm{PATH}}$. As described in the previous section, the channels used in the retrieval, the RT is in the linear regime. Thus, the PWV and LWP biases are linearly related to biases in the forward modeled BT, with their relationships described by the forward model Jacobian (K). Formally, if we write the coefficients relating the $Z_{\mathrm{PATH}}$ and the retrieval bias as $e_{\mathrm{LWP}}$ and $e_{\mathrm{PWV}}$, then the forward model perturbation can be expressed as

$$
\begin{aligned}
& {\left[\begin{array}{l}
\delta T B_{23.84 \mathrm{GHz}} \\
\delta T B_{31.4 \mathrm{GHz}}
\end{array}\right]=} \\
& {\left[\begin{array}{l}
K_{23.84 \mathrm{GHz}, \text { PWV }} K_{23.84 \mathrm{GHz}, \mathrm{LWP}} \\
K_{31.4 \mathrm{GHz}, \mathrm{PWV}} K_{31.4 \mathrm{GHz}, \mathrm{LWP}}
\end{array}\right]\left[\begin{array}{l}
e_{\mathrm{LWP}} Z_{\mathrm{PATH}} \\
e_{\mathrm{PWV}} Z_{\mathrm{PATH}}
\end{array}\right]}
\end{aligned}
$$

or 


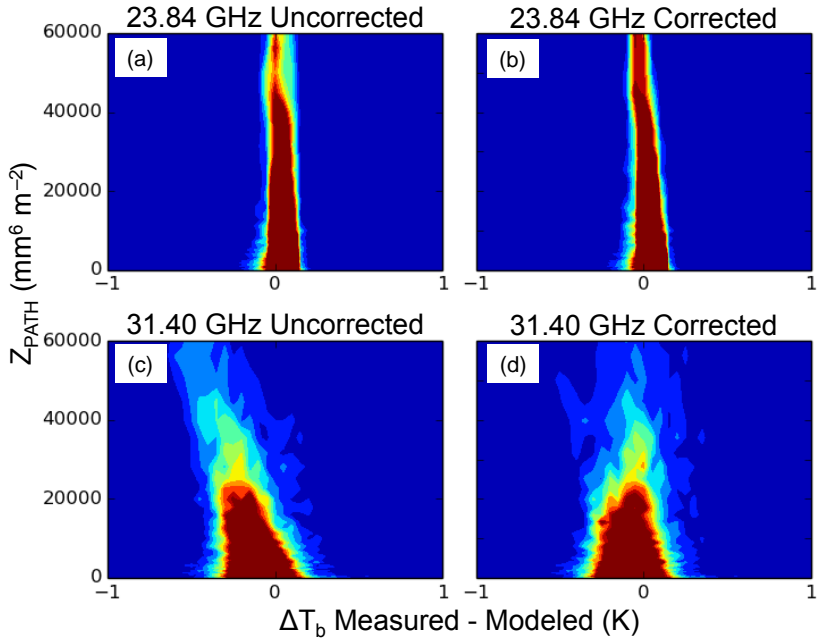

Figure 4. Histograms of the MMCR $Z_{\text {PATH }}$ and the difference between the measured and modeled BT at 23.84 and $31.40 \mathrm{GHz}$ before and after the linear correction are shown above. Contour levels are linearly spaced, showing counts per factor of $10^{0.05}$ in $Z_{\text {PATH }}$ and per $0.05 \mathrm{~K}$ in BT difference. The $y$ axis is truncated to $6 \times 10^{4} \mathrm{~mm}^{6} \mathrm{~m}^{-2} Z_{\text {PATH }}$ to highlight the correction in the low ice optical depth cases. Red signifies 50 and higher counts and blue signifies fewer than five counts. Plots are linear in both axes. The uncorrected $31.40 \mathrm{GHz}$ channel (c) has a negative bias as a function of the $Z_{\text {PATH }}$. The slope of the uncorrected $31.40 \mathrm{GHz}$ (c) histogram yields the value of $\Delta T_{\mathrm{b}} / \Delta Z_{\mathrm{PATH}}$ used in the linear correction. For both low-frequency channels, once the correction is applied, no dependence on $Z_{\text {PATH }}$ is present $(\mathbf{b}, \mathbf{d})$.

$\delta \boldsymbol{T} \boldsymbol{B}=\mathbf{K} \boldsymbol{e} Z_{\mathrm{PATH}}$.

Inverting Eq. (3) to solve for the $e$ coefficients yields:

$\boldsymbol{e}=\mathbf{K}^{-1} \delta \boldsymbol{T} \boldsymbol{B} \frac{1}{Z_{\mathrm{PATH}}}$

The linear relationship between $\delta \boldsymbol{T} \boldsymbol{B}$ and $Z_{\mathrm{PATH}}$ can then be estimated from Fig. 4a and c, by measuring the slope of the point distribution. For the $23.84 \mathrm{GHz}$ result, the slope is zero, which is due to compensating errors in LWP and PWV. For $31.40 \mathrm{GHz}$, the slope is approximately $-3.3 \times 10^{-4} \mathrm{~K}$ per $\left(\mathrm{mm}^{6} \mathrm{~m}^{-2}\right)$. Inserting these values into Eq. (4) yields a value of $-1.3 \times 10^{-4} \mathrm{~g} \mathrm{~m}^{-2}\left(\mathrm{~mm}^{6} \mathrm{~m}^{-2}\right)^{-1}$ for $e_{\mathrm{LWP}}$ and $4.4 \times 10^{-6} \mathrm{~cm}\left(\mathrm{~mm}^{6} \mathrm{~m}^{-2}\right)^{-1}$ for $e_{\mathrm{PWV}}$.

To utilize these corrections in our modeling framework, the $Z_{\mathrm{PATH}}$ from the MMCR is multiplied by the scaling factor, and the PWV and LWP are adjusted accordingly (for example, for a $Z_{\text {PATH }}$ of $10^{4} \mathrm{~mm}^{6} \mathrm{~mm}^{-2}$, the correction would reduce the LWP by $1.3 \mathrm{~g} \mathrm{~m}^{-2}$ and increase the PWV by $0.044 \mathrm{~cm})$ :

$L W P_{\text {corrected }}=L W P_{\text {retrieved }}+e_{\mathrm{LWP}} \times Z_{\mathrm{PATH}}$,

$P W V_{\text {corrected }}=P W V_{\text {retrieved }}+e_{\mathrm{PWV}} \times Z_{\mathrm{PATH}}$.
The corrected PWV and LWP are then used in the forward RT simulation with the SOI framework.

Returning to Fig. 3, we show the effect of these corrections for a standard profile at Summit with $0.1 \mathrm{~cm}$ PWV and $20 \mathrm{~g} \mathrm{~m}^{-2}$ LWP. The top panel a shows the simulated downwelling microwave radiance spectrum with no ice included in the simulation, and the simulated spectrum with the biased PWV and LWP obtained by the retrieval. The second panel $b$ shows the same simulated data after subtracting the simulated spectrum with no ice. The effect of the biased LWP and PWV on the microwave spectrum are shown independently (blue and green lines, respectively) and combined (cyan line). The residuals that are minimized by the retrieval (observed radiance minus forward model radiance) are the differences between the cyan line and the black "X"s. We see the compensating biases at $23.84 \mathrm{GHz}$, which minimizes the magnitude of the residuals at $23.84 \mathrm{GHz}$, as well as the opposite signs for the residuals at $31 \mathrm{GHz}$ (negative) and $90 \mathrm{GHz}$ (positive). The cyan line represents the retrieval's solution to minimizing the residuals when it cannot correctly account for the ice signature, which impacts the observations from high-frequency microwave channel $(90 \mathrm{GHz})$.

Comparison of the MWR observed data with the radiative transfer model - using the LWP and PWV corrections for ice - for the JJA season from 2010 through 2013 for LWP of less than $40 \mathrm{~g} \mathrm{~m}^{-2}$ in the 23.84 and $31.40 \mathrm{GHz}$ channels are insensitive with respect to the integrated reflectivity (as seen in Fig. 4b and d). This correction is successful in removing the high (low) LWP (PWV) incorporated from the ice signal, as the $31.40 \mathrm{GHz}$ channel comparison shows no dependence on moderate values of $Z_{\text {PATH }}$. With this successful evaluation of the ice-influenced LWP and PWV, we can rerun the model on the other channels and characterize the signature from the ice hydrometeors because $e_{\mathrm{LWP}}$ and $e_{\mathrm{PWV}}$ are frequency independent.

\section{Observed brightness temperature differences from ice}

We present the LWP and PWV corrected results for the $23.84,31.40,90$, and $150 \mathrm{GHz}$ channels. The lowerfrequency MWR channels exhibit insensitivity to the ice (Fig. 4b and d), while the higher-frequency MWR channels exhibit enhanced BTs when ice is present (Fig. 5). Additionally, we present data from a co-located $225 \mathrm{GHz}$ MWR, which exhibits even larger BT differences with respect to the ice. Finally, we recast the results from these five MWR channels and compare them to each other. We also show preliminary results from a simple radiative transfer simulation as a first-order comparison of modeled results against the MWR observed ice signature enhanced BTs in the 90, 150, and $225 \mathrm{GHz}$ channels. 


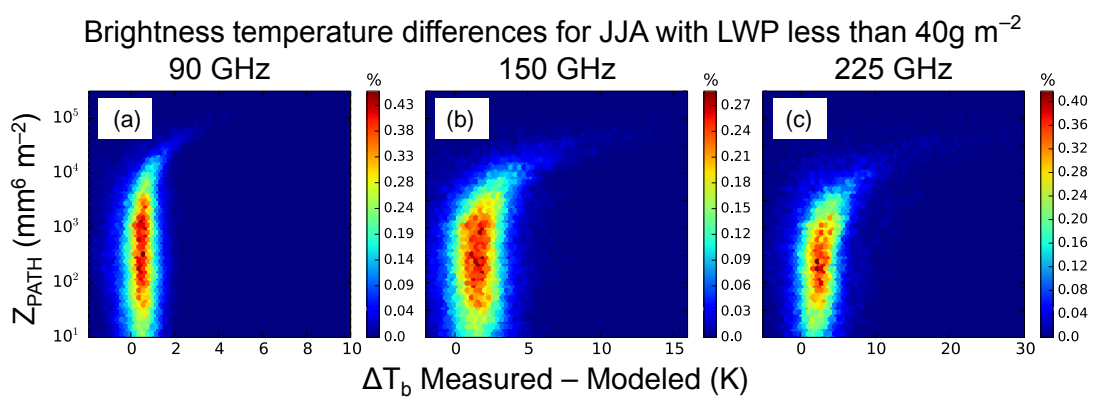

Figure 5. Brightness temperature differences between the MWRHF and the MWRHF-225 observations and the modeled gas and liquid contributions after implementing the LWP correction for ice for the 90, 150, and $225 \mathrm{GHz}$ channels. The count histogram is binned logarithmically in $Z_{\mathrm{PATH}}$ and linearly in $\Delta T_{\mathrm{b}}$, shown as percentage of total observation count per bin (same as Fig. 2). The high-frequency channels show a dependence of the difference in brightness temperature and the $Z_{\mathrm{PATH}}$ from the MMCR - thus, indicating an increasing brightness temperature in these channels with increasing total ice amount in the column. Additionally, the sensitivity to the ice signature increases as a function of higher frequency. The $Z_{\mathrm{PATH}}$ value where the ice signature $\mathrm{BT}$ enhancement begins is lower in the 150 versus the $90 \mathrm{GHz}$ channel (b, c, respectively) and lowest in the $225 \mathrm{GHz}(\mathbf{c})$. We note that there is a clear-sky bias in all three channels, but the magnitude of this bias is smaller than the radiometric uncertainty of the HFMWR observations. We are unable at this time to determine if this bias is due to calibration uncertainty in the radiometer or the result of forward model error.

\subsection{Brightness temperature differences with corrected LWP and PWV}

All data presented are events in JJA with LWP of less than $40 \mathrm{~g} \mathrm{~m}^{-2}$. The measured MWR observations are compared to the radiative transfer model including the LWP and PWV corrections for ice. The results for the lower-frequency channels, shown in Fig. $4 \mathrm{~b}$ and d, no longer depend on the $Z_{\mathrm{PATH}}$ - they should be insensitive to ice for most $Z_{\mathrm{PATH}}$. In the high-frequency channels, 90 and $150 \mathrm{GHz}$, there is clear relationship between $\mathrm{BT}$ difference and $Z_{\mathrm{PATH}}$ indicative of ice enhanced BTs (Fig. 5a and b). At the highest observed $Z_{\text {PATH }}$ values (about $10^{5} \mathrm{~mm}^{6} \mathrm{~m}^{-2}$ ), BTs are enhanced anywhere from 3 to $7 \mathrm{~K}$ in the $90 \mathrm{GHz}$ channel and 10 to $30 \mathrm{~K}$ in the $150 \mathrm{GHz}$ channel.

\subsection{Brightness temperature differences at $225 \mathrm{GHz}$}

Co-located with the ICECAPS measurements is the ASIAA a very high-frequency MWRHF-225, which allows us to extend this study to include a $225 \mathrm{GHz}$ channel. As the effect of ice on this frequency from ground observations has not yet been explored, the observed ice effect in the $225 \mathrm{GHz}$ channel is a new application of this instrument. As expected, the $225 \mathrm{GHz}$ exhibits a large BT enhancement due to ice (Fig. 5c). The MWRHF-225 was deployed in mid-2011, so the data set is somewhat smaller than the ICECAPS data set already described. In addition, the MWRHF-225 does have slightly different time coverage (e.g., the instrument downtime and QC flags are disjoint from the HATPRO and MWRHF). The data set with all five MWR channels covers only the union where all instruments collected good data. At the highest $Z_{\text {PATH }}$ values within the combined data sets in JJA from 2011 to 2013, the $225 \mathrm{GHz}$ has enhanced BTs of up to $50 \mathrm{~K}$ at the highest Zpath. The $225 \mathrm{GHz}$ results continue the trend seen in the other high-frequency channels (150 and $90 \mathrm{GHz}$ ): the $Z_{\mathrm{PATH}}$ value above which the $\mathrm{BT}$ enhancement occurs appears to decrease as the MWR frequency increases, implying increased sensitivity to the ice (Fig. 5).

\subsection{Multi-frequency comparison of brightness temperatures differences}

By plotting the difference in the observed minus calculated BTs in the MWR channels as a function of each other, one may gain insight about the spectral character of the ice signature in the microwave. Figure 6 depicts the BT difference of four of the MWR channels with respect to that of the $90 \mathrm{GHz}: 23.84,31.40,150$, and $225 \mathrm{GHz}$. Additionally, the binned values of the BT differences are colored by logarithm of the average $Z_{\mathrm{PATH}}$ within the bin, thus providing a visual reference for the relative ice amount.

In the top of Fig. 6 (panels a and b), the 23.84 and $31.40 \mathrm{GHz}$ BT differences are plotted and binned on the $y$ axis versus the values for the $90 \mathrm{GHz}$. Though the $Z_{\mathrm{PATH}}$ values increase as a function of the difference in BT in the $90 \mathrm{GHz}$, both the 23.84 and $31.40 \mathrm{GHz}$ have the same $Z_{\mathrm{PATH}}$ values throughout most cases (i.e., the $Z_{\text {PATH }}$ is neutral in the $y$ axis for all but the highest $Z_{\mathrm{PATH}}$ ), which is expected as the lower-frequency channels are comparatively insensitive to the ice. However, in panel $\mathrm{c}$ of Fig. 6, the observed enhanced BT at $150 \mathrm{GHz}$ is plotted versus the $90 \mathrm{GHz}$ and there is an approximately linear relationship between the ice effects at the two frequencies - with a slope of about $4 \mathrm{~K} \mathrm{BT}$ difference in $150 \mathrm{GHz}$ for every $1 \mathrm{~K}$ in $90 \mathrm{GHz}$. For both the 90 and $150 \mathrm{GHz}$, as the difference in the BT increases the

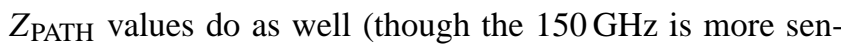
sitive to the $Z_{\text {PATH }}$ than the $90 \mathrm{GHz}$ and therefore the effect of the BT enhancement occurs at a lower $Z_{\mathrm{PATH}}$ value). In 
Multi-frequency comparisons - JJA with LWP less than $40 \mathrm{~g} \mathrm{~m}^{-2}$
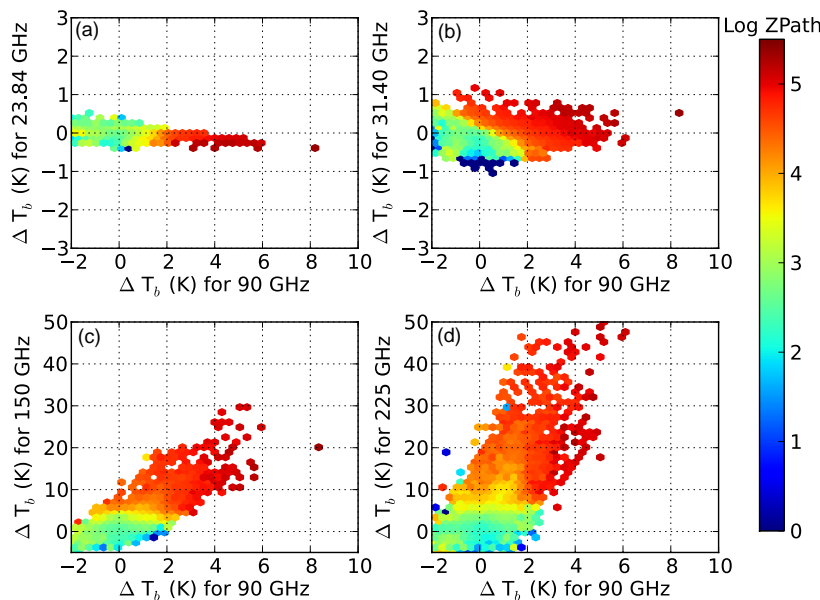

Figure 6. Multi-frequency plots of the BT difference in channels $23.84,31.40,150$, and $225 \mathrm{GHz}$ as compared to the $90 \mathrm{GHz}$ channel. The binned values of BT difference are colored according to logarithm of the average $Z_{\text {PATH }}$ values. In the top two panels, the lower-frequency channels are plotted against $90 \mathrm{GHz}(\mathbf{a}, \mathbf{b})$ and in the bottom two panels, the 150 and $225 \mathrm{GHz}$ are plotted against the $90 \mathrm{GHz}(\mathbf{c}, \mathbf{d})$.

the last plot in Fig. 6 (panel d), we compare the enhanced BT values in the $225 \mathrm{GHz}$ channel to those in $90 \mathrm{GHz}$ and again have a linear relationship between the ice effects in the two channels. Additionally, the slope of the 225 versus the $90 \mathrm{GHz}$ BT differences is steeper than the 150 versus $90 \mathrm{GHz}$ - for every $1 \mathrm{~K}$ in $90 \mathrm{GHz}$, there is a corresponding $10 \mathrm{~K}$ difference in the $225 \mathrm{GHz}$. As with the 90 and $150 \mathrm{GHz}$ case, the 90 and $225 \mathrm{GHz}$ multi-frequency plot shows increasing $Z_{\text {PATH }}$ values as a function of larger BT differences in both channels.

\subsection{Comparison of ice signatures observed with scattering model results}

Now that we have an estimate of the passive microwave ice signature, we can compare it to modeled results with our SOI framework, described in Sect. 2.3. We can find the difference in modeled BTs in the presence of ice using SOI by running the model twice: once including ice with contributions from the atmospheric gases and once with only the gases. The difference between these two runs produce differences in BTs that allow for direct comparison with our multi-frequency results (Fig. 6), and an assessment of the ice microwave optical property models for the ice hydrometeors at Summit, Greenland.

For a first-order ice habit study, we used the temperaturedependent ice particle size distribution parameterization from Field et al. (2007) (hereafter F07) for the particle size distribution (PSD), which is developed from airborne stratiform ice cloud in situ measurements in the midlatitudes. Ad-
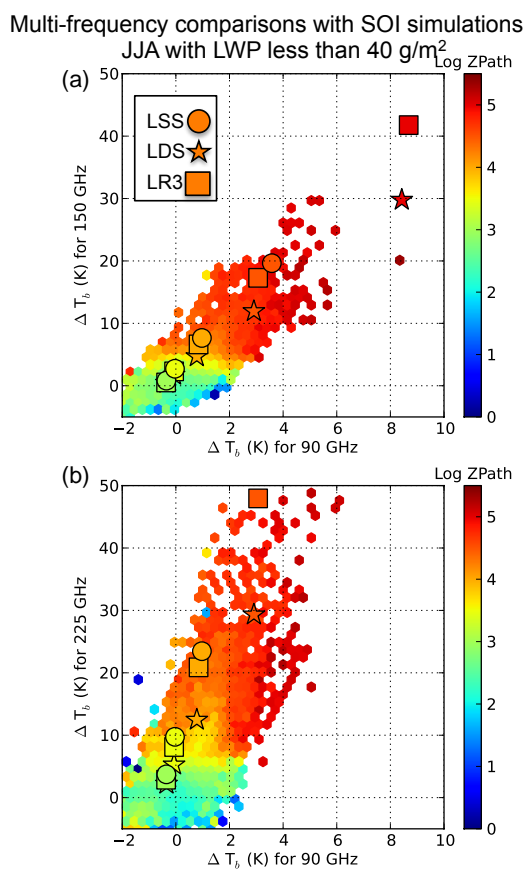

Figure 7. SOI simulated BT differences plotted on top of the observations for the 150 versus $90 \mathrm{GHz}$ and 225 versus $90 \mathrm{GHz}$ channels (a and $\mathbf{b}$, respectively). In both examples, the slopes of the simulations agree well with the observations.

ditionally, we used information from the Liu database of microwave single-scattering properties for three-bullet rosettes (LR3), sectored snowflakes (LSS), and dendrites (LDS) for ice habit characteristics (Liu, 2008; note that these are the same ice habits used in the K10 study). The PSD, ice habit, and radar backscatter cross section information are used to convert the MMCR reflectivity measurements to ice water content (IWC). This IWC is then recombined with the PSD and ice habit information and the microwave optical properties at the specific MWR frequencies, yielding the layer optical properties needed to simulate the passive MWR measurements (see Kulie et al., 2010, for further details). The SOI model uses these layer optical properties to calculate BTs at MWR frequencies. Finally, the emissivity of the snow surface is assumed to be 0.6, consistent with Yan et al. (2008) based on common snow surface conditions at Summit Station.

For an initial test of the model, we generate a synthetic $1 \mathrm{~km}$ thick ice cloud with a range in MMCR $Z_{\text {PATH }}\left(10^{3}\right.$ $10^{5} \mathrm{~mm}^{6} \mathrm{~m}^{-2}$ ), inserted at $1-2 \mathrm{~km}$ above Summit in a temperature and water vapor profile typical for summer months at the site. We make no distinction between precipitating ice and cloud ice in these simulations. The MMCR derived $Z_{\text {PATH }}$ is evenly distributed throughout the $1 \mathrm{~km}$ synthetic cloud. No liquid water cloud was included. The SOI modeled ice results with respect to the multi-frequency observations are shown in Fig. 7. The modeled LDS, LSS, and LR3 
ice habits are over-plotted on the observations and show a similar slope for both the 150 versus $90 \mathrm{GHz}$ and the 225 versus $90 \mathrm{GHz}$ cases (panels a and $\mathrm{b}$, respectively). Though the slope is similar, the equivalent $Z_{\text {PATH }}$ values for the simulations show slightly larger BT differences than those seen in the measurements.

The small differences between the SOI model results and the observations with regard to equivalent $Z_{\mathrm{PATH}}$ may stem from the ice habit assumptions and/or the PSD used for these initial results. First of all, we can run SOI for only a single habit at a time and the model runs for these habits should bound the observations if assumptions made for the PSD are correct. The F07 parameterization may not adequately represent PSDs at Summit as this parameterization is derived from midlatitude flight campaign measurements of ice stratiform clouds and may very well be not at all applicable to the arctic (Field et al., 2005, 2007). Additionally, the F07, parameterization assumes a particle mass-size relationship appropriate for aggregated ice particles, while non-aggregated, pristine ice crystals are commonly observed at Summit (Shupe et al., 2013). Furthermore, the temperatures observed in the F07 parameterization are much higher than those at Summit and therefore the growth mechanisms of the ice hydrometeors in this PSD may be different than those in the Arctic. Future work will explore other PSDs and particle size relationships, which will aid our understanding of the ice habits at Summit. A recent installation of a Multi-Angle Snowflake Camera (MASC; Garrett et al., 2012) to ICECAPS will gather more information on ice habits.

\subsection{Future work on the LWP and PWV estimate in the presence of ice}

The above results are based on our first-order assessment of the ice-influenced LWP and PWV biases. Our current correction is defined in terms of the three-channel MWRRET retrieved LWP. As noted in Sect. 2.1.2, this retrieval is used for this study as it is more sensitive to and has better precision for low LWPs. One possible BT correction can be estimated by examining specific "dry snow" cases (i.e., extremely low LWP and high $Z_{\mathrm{PATH}}$ ), and by using the results from the present analysis. Additionally, we can compare these "dry snow" cases with independent LWP measurements using the mixed-phase cloud property retrieval algorithm (MIXCRA; Turner, 2007). By using the TKC15 liquid water absorption model in MWRRET, which is more spectrally accurate at cloud liquid water temperatures below $0{ }^{\circ} \mathrm{C}$, we were able to recover many high $Z_{\mathrm{PATH}}$ cases that we found were previously discarded using the Liebe91 model. We believe that using TKC15 over the Liebe91 model reduced some of the small bias errors in our method and is a more appropriate choice for modeling cloud liquid water at Summit. Ultimately, the goal would be to create a coincident, multi-instrument retrieval of the LWP, PWV, and IWP under all atmospheric conditions.

\section{Conclusions}

This study first examined cloud and precipitation statistics derived from the MMCR and partitioned the data with a specified LWP derived from the MWR. By limiting our study to low LWP (less than $40 \mathrm{~g} \mathrm{~m}^{-2}$ ), we identify likely precipitating cases and then compared MWR BT observations against modeled BT contributions from gas and liquid components. This comparison enabled us to isolate a signature from the precipitating ice in the high-frequency MWR channels. The enhanced BT at the 90,150 , and $225 \mathrm{GHz}$ is the ice signature for the majority of precipitating cases at Summit Station for the summer seasons of 2010-2013.

We identified a bias in the current MWRRET retrieved LWP and PWV caused by the ice signature and utilization of 23.84, 31.40, and $90 \mathrm{GHz}$ channels as part of this study, and developed and applied a first-order correction (described in Sect. 4). The bias correction to the three-channel retrieval is not the focus of this study, but had to be addressed to quantify the ice signature in at microwave frequencies. Overall, the LWP and PWV bias due to ice occurs in a small fraction of the total data, and is relatively small in magnitude. For example, the high $Z_{\text {PATH }}\left(>10^{4} \mathrm{~mm}^{6} \mathrm{~m}^{-2}\right)$ cases accounts for fewer than $2 \%$ of all available Summit MMCR data ( $4 \%$ if limited to JJA), and the LWP and PWV adjustments are $-1.3 \mathrm{~g} \mathrm{~m}^{-2}$ and $0.044 \mathrm{~cm}$, respectively, for $Z_{\mathrm{PATH}}$ of $10^{4} \mathrm{~mm}^{6} \mathrm{~m}^{-2}$. Thus, the impact of the LWP bias on seasonal statistics will be minimal. However, an accurate LWP retrieval in the presence of ice is important for precipitation specific cases. In addition, the small number of high $Z_{\mathrm{PATH}}$ cases represent the heaviest snowfalls and thus are important for capturing the annual snowfall (Castellani et al., 2015).

The multi-frequency relationships in the high-frequency MWR channels, illustrated in our results in Sect. 5.3, show a linear relationship between the $90 \mathrm{GHz}$ channel versus both the 150 and $225 \mathrm{GHz}$ channels and increasing $Z_{\mathrm{PATH}}$ values as a function of larger BT differences in each case. The initial SOI model runs for a synthetic ice cloud agree well with the observations, in both the relative slope and in $Z_{\mathrm{PATH}}$ magnitude. These results can also act as a starting point to a more rigorous LWP and PWV correction as described in Sect. 5.5. In future work, it may be possible to combine the MWRRET algorithm with data from the MMCR to create a robust joint retrieval of the LWP and the microwave ice signature. This will recover data at the large $Z_{\mathrm{PATH}}$ values and should lead to unbiased retrievals of LWP and PWV directly. Ultimately, a joint retrieval of LWP, PWV, and ice water path (IWP) is desired.

To accurately retrieve IWP from the measured ice signature, we need accurate descriptions of the ice habit, surface temperature and emissivity, and ice PSDs more representative of conditions at Summit. For future work, we hope to employ a PSD with a better fit to the Summit conditions and eventually have ICECAPS instrumentation capable of measuring a PSD in situ. The measured ice signature technique 
outlined in this work is a novel approach to better understand ice hydrometeors and could prove to be a powerful tool in future ground and remote sensing applications.

Acknowledgements. ICECAPS and associated research in this study is supported by NSF PLR1304544, PLR1355654, and PLR1303879. Partial support is also provided by NASA NNX12AQ76G and NNX13AG47G. We appreciate the advice and contributions from Stefan Kneifel, the use of the ASIAA MWR at Summit Station (P.I. Ming-Tang Chen), our colleague V. P. Walden, and all the technicians and support staff that keep the ICECAPS suite running. Ceilometer measurements were provided by the US Department of Energy's Atmospheric Radiation Measurement Program.

Edited by: J.-Y. C. Chiu

\section{References}

Ackerman, T. P. and Stokes, G. M.: The Atmospheric Radiation Measurement Program, Phys. Today, 55, 39-44, 2003.

Bennartz, R. and Bauer, P.: Sensitivity of microwave radiances at $85-183 \mathrm{GHz}$ to precipitating ice particles, Radio Sci., 38, 8075, doi:10.1029/2002RS002626, 2003.

Castellani, B. B., Shupe, M. D., Hudak, D. R., and Sheppard, B. E.: The annual cycle of snowfall at Summit, Greenland, J. Geophys. Res., 120, 6654-6668, doi:10.1002/2015JD023072, 2015.

Church, J. A.: Changes in sea level, Climate Change 2001: The Scientific Basis, Cambridge University Press, 639-693, 2001.

Clough, S. A., Shephard, M. W., Mlawer, E. J., Delamere, J. S., Iacono, M. J., Cady-Pereira, K., Boukabara, S., and Brown, P. D.: Atmospheric radiative transfer modeling: a summary of the AER codes, J. Quant. Spectrosc. Ra., 91, 33-244, 2005.

Crewell, S. and Löhnert, U.: Accuracy of cloud liquid water path from ground-based microwave radiometry 2. Sensor accuracy and synergy, Radio Sci., 38, 8042-8051, doi:10.1029/2002RS002634, 2003.

Crewell, S., Ebell, K., Löhnert, U., and Turner, D. D.: Can liquid water profiles be retrieved from passive microwave zenith observations?, Geophys. Res. Lett., 36, L06803, doi:10.1029/2008GL036934, 2009.

Dansgaard, W., Johnsen, S. J., Clausen, H. B., Dahl-Jensen, D., Gundestrup, N. S., Hammer, C. U., Hvidberg, C. S., Steffensen, J. P., Sveinbjörnsdottir, A. E., Jouzel, J., and Bond, G.: Evidence for general instability of past climate from a 250-kyr ice-core record, Nature, 364, 218-220, 1993.

Deeter, M. N. and Evans, K. F.: A novel ice-cloud retrieval algorithm based on the Millimeter-Wave Imaging Radiometer (MIR) 150-and 220-GHz channels, J. Appl. Meteorol., 39, 623-633, 2000.

Field, P. R., Hogan, R. J., Brown, P. R. A., Illingworth, A. J., Choularton, T. W., and Cotton, R.: Parameterization of iceparticle size distributions for mid-latitude stratiform cloud, Q. J. Roy. Meteor. Soc., 131, 1997-2017, doi:10.1256/qj.04.134, 2005 .
Field, P. R., Heymsfield, A. J., and Bansmer, A.: Snow Size Distribution Parameterization for Midlatitude and Tropical Ice Clouds, J. Atmos. Sci., 64, 4346-4365, 2007.

Frisch, A. D., Lenschow, D. H., Fairall, C. W., Schubert, W. H., and Gibson, J. S.: Doppler Radar Measurements of Turbulence in Marine Stratiform Cloud during ASTEX, J. Atmos. Sci., 52, 2800-2808, 1995.

Garrett, T. J., Fallgatter, C., Shkurko, K., and Howlett, D.: Fall speed measurement and high-resolution multi-angle photography of hydrometeors in free fall, Atmos. Meas. Tech., 5, 26252633, doi:10.5194/amt-5-2625-2012, 2012.

Heidinger, A. K., O'Dell, C. W., Bennartz, R., and Greenwald, T.: The Successive-Order-of-Interaction Radiative Transfer Model. Part I: Model Development, J. Appl. Meteorol. Clim., 45, 1388$1402,2006$.

Hong, G., Heygster, G., Miao, J., and Kunzi, K.: Detection of tropical deep convective clouds from AMSU-B water vapor channels measurements, J. Geophys. Res., 110, D05205, doi:10.1029/2004JD004949, 2005.

Johnson, B. T., Petty, G. W., and Skofronick-Jackson, G.: Microwave Properties of Ice-Phase Hydrometeors for Radar and Radiometers: Sensitivity to Model Assumptions, J. Appl. Meteorol. Clim., 51, 2152-2171, 2012.

Kneifel, S., Löhnert, U., Battaglia, A., Crewell, S., and Siebler, D.: Snow scattering signals in ground based passive microwave radiometer measurements, J. Geophys. Res., 115, D16214, doi:10.1029/2010JD013856, 2010.

Kneifel, S., Bennartz, R., and Kulie, M. S.: A triple-frequency approach to retrieve microphysical snowfall parameters, J. Geophys. Res., 116, D11203, doi:10.1029/2010JD015430, 2011.

Kneifel, S., Redl, S., Orlandi, E., Löhnert, U., Cadeddu, M. P., Turner, D. D., and Chen, M.-T.: Absorption properties of supercooled liquid water between 31 and $225 \mathrm{GHz}$ : Evaluation of absorption models using ground-based observations, J. Appl. Meteorol. Clim., 53, 1028-1045, 2014.

Kulie, M. S. and Bennartz, R.: Utilizing space-borne radars to retrieve dry snowfall, J. Appl. Meteorol. Clim., 48, 2564-2580, doi:10.1175/2009JAMC2193.1, 2009.

Kulie, M. S., Bennartz, R., Greenwald, T., Chen, Y., and Weng, F.: Uncertainties in Microwave Properties of Frozen Precipitation: Implications for Remote Sensing and Data Assimilation, J. Atmos. Sci., 67, 3471-3487, 2010.

Liebe, H., Hufford, G., and Manabe, T.: A model for the permittivity of water at frequencies below $1 \mathrm{THz}$, International Journal of Infrared Millimeter and Terahertz Waves, 12, 659-675, 1991.

Liu, G.: A database of microwave single-scattering properties for nonspherical ice particles, B. Am. Meteorol. Soc., 89, 1563$1570,2008$.

Löhnert, U. and Crewell, S.: Accuracy of cloud liquid water path from ground-based microwave radiometry, 1, Dependency on cloud model statistics, Radio Sci., 38, 8041, doi:10.1029/2002RS002654, 2003.

Matsushita, S., Chen, M., Martin-Cocher, P., Asada, K., Chen, C., Inoue, M., Paine, S., Turner, D. D., and Steinbring, E.: $225 \mathrm{GHz}$ Atmospheric Opacity Measurements from Two Arctic Sites, Astrophysics from Antarctica Proceedings IAU Symposium, 8, 204-207, doi:10.1017/S1743921312016882, 2013. 
Moran, K. P., Martner, B., Post, M. J., Kropfli, R. A., Welsh, D. C., and Widener, K. B.: An unattended cloud-profiling radar for use in climate research, B. Am. Meteorol. Soc., 79, 443-455, 1998.

O’Dell, C. W., Heidinger, A. K., Greenwald, T., Bauer, P., and Bennartz, R.: The Successive-Order-of-Interaction Radiative Transfer Model. Part II: Model Performance and Applications, J. Appl. Meteorol. Clim., 45, 1403-1413, 2006.

Petty, G. W. and Huang, W.: Microwave backscatter and extinction by soft ice spheres and complex snow aggregates, J. Atmos. Sci., 67, 769-787, 2010.

Pruppacher, H. R. and Klett, J. D.: Microphysics of clouds and precipitation, Kluwer Academic Publishers, the Netherlands, 2000.

Rose, T., Crewell, S., Löhnert, U., and Simmer, C.: A network suitable microwave radiometer for operational monitoring of the cloudy atmosphere, Atmos. Res., 75, 183-200, doi:10.1016/j.atmosres.2004.12.005, 2005.

Shupe, M. D., Walden, V. P., Eloranta, E., Uttal, T., Campbell, J. R., Starkweather, S. M., and Shiobara, M.: Clouds at Arctic atmospheric observatories, Part I. Occurrence and macrophysical properties, J. Appl. Meteorol. Clim., 50, 626-644, 2011.

Shupe, M. D., Turner, D. D., Walden, V. P., Bennartz, R., Cadeddu, M., Castellani, B. B., Cox, C. J., Hudak, D. R., Kulie, M. S., Miller, N. B., Neely, R. R., Neff, W. D., and Rowe, P. M.: High and Dry: New Observations of Tropospheric and Cloud Properties above the Greenland Ice Sheet, B. Am. Meteorol. Soc., 94, 169-186, 2013.

Turner, D. D.: Improved ground-based liquid water path retrievals using a combined infrared and microwave approach, J. Geophys. Res., 112, D15204, doi:10.1029/2007JD008530, 2007.
Turner, D. D., Lesht, B. M., Clough, S. A., Liljegren, J. C., Revercomb, H. E., and Tobin, D. C.: Dry bias and variability in Vaisala radiosondes: The ARM experience, J. Atmos. Ocean. Tech., 20, 117-132, 2003.

Turner, D. D., Clough, S. A., Liljegren, J. C., Clothiaux, E. E., Cady-Pereira, K., and Gaustad, K. L.: Retrieving Liquid Water Path and Precipitable Water Vapor From the Atmospheric Radiation Measurement (ARM) Microwave Radiometers, IEEE T. Geosci. Remote Sens., 45, 3680-3690, 2007a.

Turner, D. D., Vogelmann, A. M., Austin, R. T., Banard, J., CadyPereira, K., Chiu, J. C., Clough, S. A., Flynn, C., Khaiyer, M. M., Liljegren, J. C., Johnson, K., Min, Q., Minnis, P., O’Hirok, W., Wang, Z., and Wiscombe, W.: Thin liquid water clouds: Their importance and our challenge, B. Am. Meteorol. Soc., 88, 177190, 2007b.

Turner, D. D., Kneifel, S., and Cadeddu, M.: An improved liquid water absorption model in the microwave for supercooled liquid water clouds, J. Atmos. Ocean. Tech., 33, 33-44, doi:10.1175/JTECH-D-15-0074.1, 2015.

Uttal, T., Starkweather, S., Drummond, J. R., et al.: International Arctic systems for observing the atmosphere (IASOA): An international polar year legacy consortium, B. Am. Meteorol. Soc., submitted, 2015.

Yan, B., Weng, F., and Meng, H.: Retrieval of snow surface microwave emissivity from the advanced microwave sounding unit, J. Geophys. Res., 113, D19206, doi:10.1029/2007JD009559, 2008. 